\title{
Gastrointestinal motor mechanisms in hyperglycaemia induced delayed gastric emptying in type I diabetes mellitus
}

\author{
M Samsom, L M A Akkermans, R J A Jebbink, H van Isselt, G P vanBerge-Henegouwen, \\ A J P M Smout
}

\begin{abstract}
Background-Hyperglycaemia delays gastric emptying, both in healthy controls and in patients with diabetes mellitus. The effect of hyperglycaemia on antroduodenal motility in diabetes has not yet been studied.
\end{abstract}

Aim-To investigate the gastrointestinal motor mechanisms involved in the hyperglycaemia induced retardation of gastric emptying in patients with type I diabetes mellitus and autonomic neuropathy. In eight diabetic patients antroduodenal manometry was performed simultaneously with scintigraphic measurement of emptying of a mixed solid-liquid meal, during euglycaemia (5-8 $\mathrm{mmol} / \mathrm{l}$ glucose) and hyperglycaemia (16-19 mmol/l glucose), on separate days, in random order.

Results-Hyperglycaemia decreased the cumulative antral motility index from $38 \cdot 3$ (range $24 \cdot 2-47 \cdot 6$ ) to $30 \cdot 8$ (range $17 \cdot 3-38 \cdot 1$ ) $(p=0.025)$ and reduced the number of antral pressure waves propagated over $\geq 4.5 \mathrm{~cm}(p=0.04)$. Duodenal phase III-like activity was seen irrespective of the glycaemic state (in three patients during euglycaemia and in four patients during hyperglycaemia). Hyperglycaemia significantly affected gastric emptying of the solid meal: it prolonged the lag phase from 20.0 minutes to $28 \cdot 5$ minutes $(p=0.02)$, increased the $50 \%$ emptying time from 73.5 minutes to 104.5 minutes $(p=0.03)$, and increased the percentage of isotope remaining in the stomach after $120 \mathrm{~min}-$ utes from $33 \cdot 5 \%$ to $46 \cdot 5 \%(p=0 \cdot 02)$. The cumulative antral motility index was correlated with the $50 \%$ emptying time $(r=0.75, p=0.02)$ during euglycaemia, but not during hyperglycaemia $(r=0 \cdot 28$, $\mathbf{p}=0 \cdot 31$ ). Liquid emptying was not influenced by the blood glucose concentration. Conclusions-Hyperglycaemia reduces postprandial antral contractile activity and its organisation in patients with type I diabetes and autonomic neuropathy. These changes in antroduodenal motility are likely to constitute the mechanism through which gastric emptying of solids is delayed during high blood glucose concentrations in these diabetic patients.

(Gut 1997; 40: 641-646)

Keywords: diabetes mellitus, scintigraphic gastric emptying, antroduodenal motility, hyperglycaemia.
The prevalence of delayed gastric emptying in patients with type I diabetes mellitus is about $50 \% .^{1-3}$ Manometric studies performed with the aim to elucidate the motor mechanisms responsible for delayed gastric emptying in this disease have shown that postprandial motor activity is often abnormal in diabetic patients. The abnormalities consist of antral hypomotility, pyloric spasm, and pathological motor patterns in the small intestine. ${ }^{4-6}$ These abnormalities in gastrointestinal motility may cause dyspeptic symptoms and may also affect glycaemic control. ${ }^{7-9}$

Autonomic neuropathy is thought to be an important causal factor in motility disorders in diabetes mellitus. ${ }^{10}$ However, the correlation between cardiovascular autonomic neuropathy tests and motility variables is poor. One of the reasons for this poor correlation is that gastrointestinal motor activity is also influenced by the blood glucose concentration, as hyperglycaemia retards gastric emptying. ${ }^{11}$

The effects of hyperglycaemia on antroduodenal motility have been studied in healthy volunteers, and showed a decreased interdigestive and postprandial antral motor activity and an increased number of isolated pyloric pressure waves during hyperglycaemia. ${ }^{12-14}$ The underlying mechanism by which hyperglycaemia affects upper gastrointestinal motility is not known. However, the fact that high blood glucose concentrations have opposite effects on gastrointestinal motor function (inhibition of antral motility and stimulation of pyloric activity) in combination with the finding that vagal-cholinergic activity is decreased by hyperglycaemia make it very likely that neuronal (vagal) control rather than smooth muscle function itself is affected by hyperglycaemia. ${ }^{15}$

Whether the effects of hyperglycaemia on antroduodenal motility are similar in diabetic patients with vagal neuropathy as in healthy volunteers has not yet been investigated. The aim of the present study was, therefore, to investigate the gastrointestinal motor mechanisms involved in the retardation of gastric emptying induced by hyperglycaemia in patients with type I diabetes mellitus and autonomic neuropathy.

Antroduodenal manometry was performed simultaneously with scintigraphic measurement of gastric emptying of a mixed solidliquid meal, during euglycaemia and hyperglycaemia. 


\section{Methods}

PATIENTS

Eight patients with insulin dependent diabetes mellitus (six women, two men), mean age 49 (range 43-67) years were studied. The patients were randomly selected from outpatients attending the endocrinology department of the University Hospital at Utrecht and the Department of Internal Medicine of the Catharina Hospital at Eindhoven for management of diabetes mellitus. The median duration of their diabetes was 22 (range 15-44) years. Although patients were not selected on the basis of gastrointestinal symptoms, in all cases gastric outlet obstruction was excluded by upper gastrointestinal endoscopy. The median glycylated haemoglobin concentration ( $\mathrm{HbAl}$ ) at the time of the study was $8.5 \%$ (range $8-11 \cdot 7 \%$, normal 4-7\%). All patients had one or more complications of diabetes mellitus such as peripheral neuropathy, nephropathy, or retinopathy. Autonomic neuropathy was evaluated using the cardiovascular autonomic neuropathy tests (maximum 5 points) according to Ewing and Clarke. ${ }^{16}$ In five patients early autonomic neuropathy $\left(2,2,2,2\right.$, and $1 \frac{1}{2}$ points) and in three patients definite autonomic neuropathy $\left(2 \frac{1}{2}, 3\right.$, and $3 \frac{1}{2}$ points) were found.

The median creatinine concentration was $87 \cdot 0$ (range $67-371$ ) $\mathrm{mmol} / \mathrm{l}$; the creatinine concentration was abnormally high in one patient. Any medication which could influence gastrointestinal motility (apart from insulin) was discontinued 48 hours before each study.

Written informed consent was obtained in all cases and the study was approved by the ethics committee of the University Hospital Utrecht.

PROTOCOI

In all patients gastric emptying and antroduodenal motility were measured simultaneously during euglycaemia (5-8 $\mathrm{mmol} / \mathrm{l})$ and hyperglycaemia (16-19 $\mathrm{mmol} / \mathrm{l})$, on two separate days at a one week interval and in random order.

Patients fasted from 2000 hours the previous day and injected $50 \%$ of their normal insulin dose on the morning of each study day. The antroduodenal catheter was introduced transnasally and initially positioned under fluoroscopic control. Subsequently, the catheter position was monitored by measurement of antroduodenal transmucosal potential difference (TMPD).${ }^{17}$ After correct positioning of the catheter two cannulas were inserted into the anticubital veins, one in each arm, one for infusion of glucose and insulin and the other for blood sampling. The blood glucose concentrations were measured every 10 minutes. Blood glucose concentrations were stabilised in either the euglycaemic or hyperglycaemic range. When blood glucose concentrations had been stable for two hours a radioisotopically labelled test meal was given at about 1330 hours. Gastric emptying and antroduodenal motility were recorded for 120 minutes after ingestion of the mixed liquid-solid meal.
MEASUREMENT OF ANTRODUODENAL PRESSURES

Antroduodenal manometry was performed with a nine channel perfused catheter (outside diameter $4.7 \mathrm{~mm}$, internal diameter $0.74 \mathrm{~mm}$ ). The catheter was stiffened with a guidewire through the central lumen $(1.33 \mathrm{~mm})$ to facilitate its introduction. Pressure sensors were located at $5,15,25,40,45,46 \cdot 5,48 \cdot 0$, and $49.5 \mathrm{~cm}$ from the tip. The four proximal side holes were positioned in the antrum. The side holes located at $40 \mathrm{~cm}$ and $45 \mathrm{~cm}$ were used to measure the antroduodenal TMPD. Manometric channels were perfused with degassed liquid at a rate of $0.3 \mathrm{ml} / \mathrm{min}$ with a low compliance pneumohydraulic pump. The antral and duodenal TMPD channels were perfused with saline from separate reservoirs and all other channels were perfused with distilled water. Pressures were measured by external transducers (DPT-200, Medisize, Hillegom, The Netherlands). The pressure signals from the six proximal side holes (four antral, two duodenal) and the TMPD were recorded on a portable data logger (Medical Measurement Systems, Enschede, the Netherlands). Whereas the storage capacity of the data logger is $1 \mathrm{MB}$, maximum data compression allowed storage of $1.9 \mathrm{MB}$. The sample frequency was $4 \mathrm{~Hz}$. A stationary MS-DOS computer served as an on line display and retrieval system. Pressure recordings were analysed only when the antral TMPD was $\leq-20$ $\mathrm{mV}$ and the duodenal TMPD was $\geq-15 \mathrm{mV}$ with a difference between the two of at least 15 $\mathrm{mV}$, indicating a correct catheter position. ${ }^{17}$

The manometric data were analysed both visually and automatically. Using commercially available software (Medical Measurement Systems, Enschede, The Netherlands) the number ( $n$ ) of pressure waves of amplitude $\geq 1.4 \mathrm{kPa}(10 \mathrm{~mm} \mathrm{Hg})$, and their mean amplitude (MA) were calculated after elimination of the artefacts such as abdominal pressure peaks, respiration, and drift of the pressure transducers. ${ }^{18}$

In addition, the motility index (MI) was calculated, defined as $\mathrm{MI}=\ln (\mathrm{n} \times \Sigma$ amplitudes +1 ). Phase III in the antrum or duodenum was defined as contractile activity at the maximum frequency for at least one minute in the antrum (three contractions/min) and for at least two minutes in the duodenum (10-12 contractions/ min), which was propagated over at least two recording sites and was followed by motor quiescence. ${ }^{19}$ When pressure waves with maximum frequency were only seen in the most distal duodenal channel or if they were not followed by motor quiescence, the pattern was called phase III-like activity. Short bursts were defined as contractile activity in the duodenum at maximum frequency $0.5-1.0$ minutes in duration without distal propagation. ${ }^{4}$ Antral pressure waves were considered to be "propagated" if the onset of the antral pressure wave at one recording site occurred within five seconds of the onset of an antral pressure wave recorded at an adjacent site. ${ }^{20}$ The number of antral pressure waves propagated over a distance $\geq 4.5 \mathrm{~cm}$ was calculated. 
MEASUREMENT OF GASTRIC EMPTYING

Gastric emptying was measured using a double isotope technique. ${ }^{21}$ Each study was performed with the patient seated in front of the scintillation camera. The solid component of the meal (pancake; $1240 \mathrm{~kJ} ; 14 \%$ protein, $15 \%$ fat, $71 \%$ carbohydrate) was labelled with ${ }^{99 \mathrm{~m}} \mathrm{Tc}$ sulphur colloid and the $150 \mathrm{ml}$ liquid component (dextrose $10 \%, 250 \mathrm{~kJ}$ ) was labelled with ${ }^{113 \mathrm{~m}}$ In-DPTA. Data were collected in one minute frames and were corrected for movement, Compton scatter, $\gamma$ ray attenuation, and radionuclide decay. ${ }^{21}$ For the solid and liquid components, the time for $50 \%$ gastric emptying and the percentage isotope remaining in the stomach after 120 minutes were calculated. When the $50 \%$ emptying time $\left(\mathrm{T}^{50}\right)$ was longer than the 120 minutes of the study period, it was calculated by extrapolating the linear emptying curve of the solid meal. Figure 3 (see later) shows the normal range (mean (2SD)) of the $50 \%$ emptying time determined in 16 healthy volunteers. These data were obtained from gastric emptying studies performed in nonintubated healthy volunteers. As it has been shown that duodenal intubation does not alter gastric emptying, these data could be used for comparison with the gastric emptying data obtained in this study. ${ }^{22}$ The lag phase for the solid meal, the time interval between ingestion of the meal, and the appearance of the first radioactivity in the duodenum, were determined visually.

\section{STABILISATION OF BLOOD GLUCOSE}

CONCENTRATIONS

Euglycaemia and hyperglycaemia were induced by infusion of $20 \%$ glucose and insulin intravenously (Actrapid, Novo Nordisk Farma BV, Zoeterwoude, The Netherlands). ${ }^{23}$ The rate of $20 \%$ glucose infusion was adjusted to maintain the blood glucose concentration at 5-8 $\mathrm{mmol} / \mathrm{l}$ or $16-19 \mathrm{mmol} / \mathrm{l}$. Blood samples were drawn from the cannula that was not used for glucose and insulin infusion, for the measurement of glucose concentrations after 10 minutes using Glukotest 1-44R strips (Boehringer Mannheim, Germany) and a portable glucose meter (Reflolux S, Boehringer Mannheim, Germany).

The blood glucose concentrations (mean (SEM)) measured during euglycaemia were $7.54(0.23) \mathrm{mmol} / \mathrm{l}$ and $18.05(0.23) \mathrm{mmol} / \mathrm{l}$ during hyperglycaemia. The glucose concentration at $\mathrm{t}=0$ minutes was $4.6(0.7) \mathrm{mmol} / \mathrm{l}$ and this had increased to $8 \cdot 4(2 \cdot 3) \mathrm{mmol} / \mathrm{l}$ at $\mathrm{t}=60$ minutes. In seven of 104 blood samples taken in the postprandial period the blood glucose concentration was between 10 and $12.5 \mathrm{mmol} / \mathrm{l}$.
STATISTICAL ANALYSIS

Data were evaluated with the Wilcoxon test (paired). Relations between antroduodenal pressures and gastric emptying were evaluated with Pearson's correlation coefficient. Data are shown as median and range, unless stated otherwise. A p value $<0.05$ was considered significant.

\section{Results}

The nasogastric intubation was well tolerated in all patients. The catheter position was correct during $94 \%$ of the recording time.

\section{ANTRODUODENAL PRESSURES}

The numbers of antral pressure waves and their amplitude recorded from the individual side holes were not significantly decreased by hyperglycaemia (Table). However, the number of antral pressure waves propagated over a distance $\geq 4.5 \mathrm{~cm}$ was lower during hyperglycaemia (Fig 1). Hyperglycaemia significantly decreased the cumulative motility index, from $38 \cdot 3(24 \cdot 2-47 \cdot 6)$ to $30 \cdot 8(17 \cdot 3-38 \cdot 1)$ $(\mathrm{p}=0.025$; Fig 2$)$.

At the level of the duodenum the number of pressure waves at the proximal duodenal recording site $(\mathrm{p}=0.04$; Table $)$ and the motility index $(13.8 v 11.8, \mathrm{p}=0.02)$ were lower during hyperglycaemia. Abnormal duodenal motility patterns consisted of short bursts in five patients during euglycaemia and in three patients during hyperglycaemia, comprising $6 \cdot 44 \%$ and $2 \cdot 27 \%$ of the total recording time during euglycaemia and hyperglycaemia respectively $(p=0 \cdot 34)$.

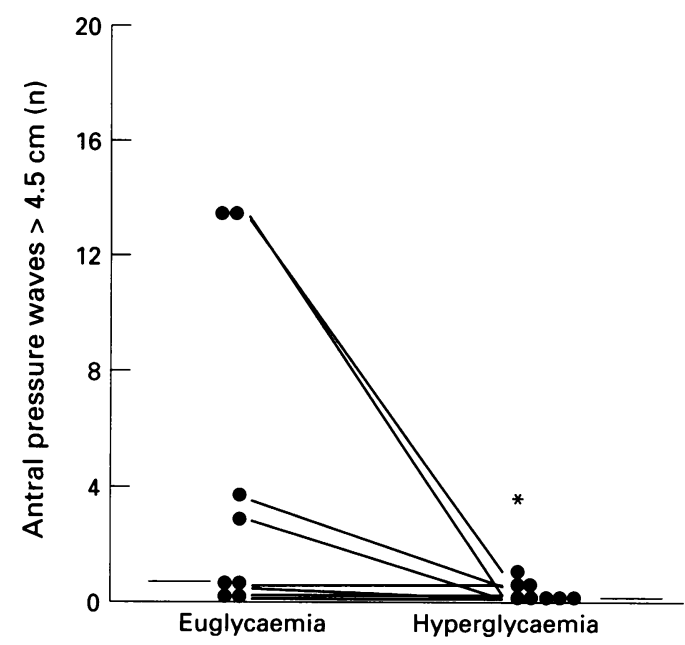

Figure 1: Individual values of the number of antral pressure waves propagated over a distance $\geq 4.5 \mathrm{~cm}$.

Hyperglycaemia reduced the number of propagated antral pressure waves in the period after the meal $(p<0 \cdot 04)$.

Number of pressure waves and amplitude (median, range) observed in the first two hours after ingestion of a meal

\begin{tabular}{|c|c|c|c|c|c|c|}
\hline $\begin{array}{l}\text { Recording } \\
\text { site }\end{array}$ & $\begin{array}{l}\text { Pressure } \\
\text { waves during } \\
\text { euglycaemia }\end{array}$ & $\begin{array}{l}\text { Pressure } \\
\text { waves during } \\
\text { hyperglycaemia }\end{array}$ & $p$ Value & $\begin{array}{l}\text { Amplitude during } \\
\text { euglycaemia }\end{array}$ & $\begin{array}{l}\text { Amplitude during } \\
\text { hyperglycaemia }\end{array}$ & $p$ Value \\
\hline $\begin{array}{l}\text { Antrum 1 } \\
\text { Antrum } 2 \\
\text { Antrum } 3 \\
\text { Antrum 4 } \\
\text { Duodenum 1 } \\
\text { Duodenum 2 }\end{array}$ & $\begin{array}{l}36(12-191) \\
82(20-236) \\
68(8-148) \\
80(19-228) \\
397(138-545) \\
612(245-494)\end{array}$ & $\begin{array}{c}10(1-215) \\
24(2-146) \\
27(5-129) \\
67(22-146) \\
186(86-369) \\
319(156-558)\end{array}$ & $\begin{array}{l}0 \cdot 06 \\
0 \cdot 09 \\
0 \cdot 30 \\
0 \cdot 14 \\
0 \cdot 04 \\
0 \cdot 09\end{array}$ & $\begin{array}{l}3 \cdot 19(0 \cdot 01-5 \cdot 79) \\
3 \cdot 03(0 \cdot 10-6 \cdot 48) \\
2 \cdot 31(0 \cdot 10-4 \cdot 23) \\
4 \cdot 49(2 \cdot 55-10 \cdot 14) \\
4 \cdot 74(3 \cdot 61-7 \cdot 04) \\
4 \cdot 32(3 \cdot 13-6 \cdot 88)\end{array}$ & $\begin{array}{l}3 \cdot 34(1 \cdot 40-5 \cdot 29) \\
2 \cdot 71(0 \cdot 95-5 \cdot 84) \\
2 \cdot 83(1 \cdot 58-5 \cdot 20) \\
4 \cdot 08(2 \cdot 50-10 \cdot 29) \\
4 \cdot 07(3 \cdot 06-5 \cdot 71) \\
4 \cdot 10(2 \cdot 73-5 \cdot 29)\end{array}$ & $\begin{array}{l}0.87 \\
0 \cdot 83 \\
0 \cdot 77 \\
0.48 \\
0.17 \\
0.77\end{array}$ \\
\hline
\end{tabular}




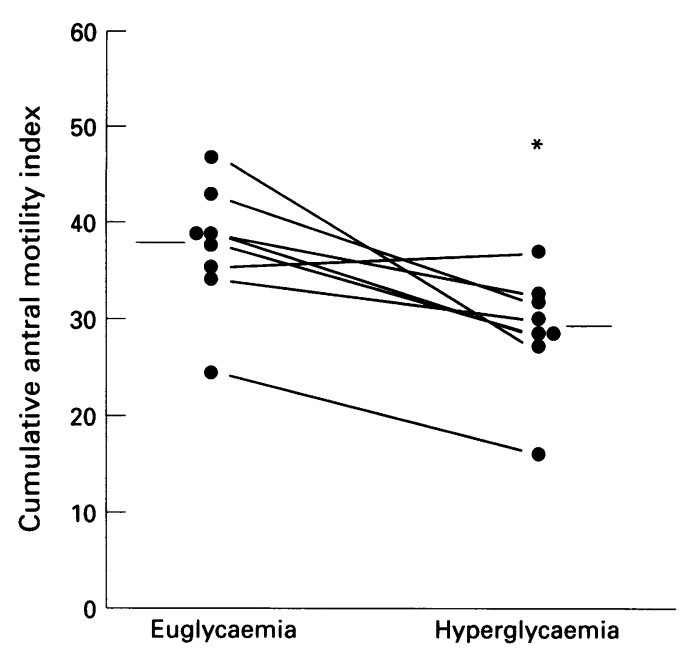

Figure 2: Individual values of the cumulative antral motility index after the meal, showing a decrease in the cumulative antral motility index during hyperglycaemia $\left({ }^{*} p<0.025\right)$.

Duodenal phase III or phase III-like activity occurred in the two hour period after the meal during euglycaemia in three patients and in four patients during hyperglycaemia. During euglycaemia, phase III or phase III-like activity was found three times, 105, 23, and 87 minutes after the meal. At this time the percentage of the solid meal in the stomach was $46 \%, 80 \%$, and $70 \%$ respectively. During hyperglycaemia phase III or phase III-like activity was found eight times in four patients. In these patients the first phase III or phase III-like activity occurred 104, 70, 55, and 93 minutes after the meal. The percentage of the solid meal remaining in the stomach at this time was $42 \%, 68 \%, 20 \%$, and $78 \%$ respectively.

\section{SCINTIGRAPHIC DATA}

\section{Solid emptying}

Emptying of the solid meal was slower during hyperglycaemia than during euglycaemia. During hyperglycaemia the lag phase was

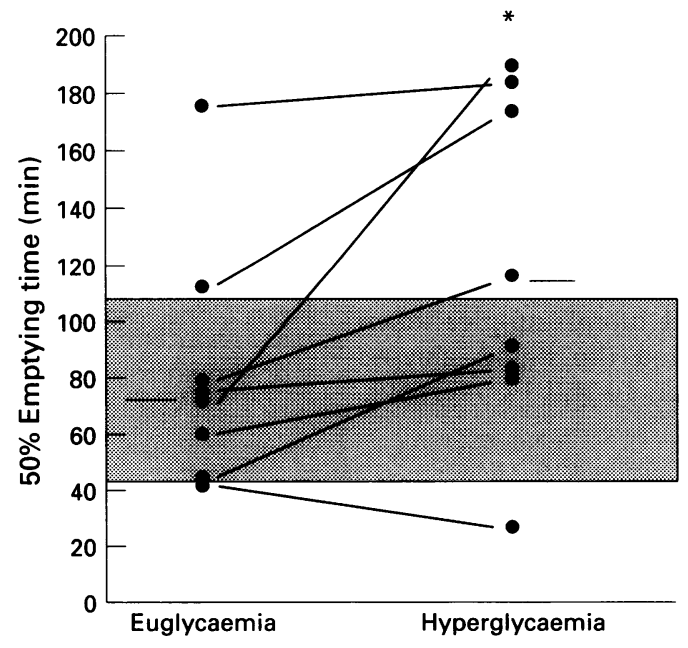

Figure 3: Individual values for gastric emptying, showing an increased $50 \%$ emptying time during hyperglycaemia $(p<0 \cdot 03)$. Shaded area shows normal range (mean (2SD)) obtained from 16 healthy volunteers. prolonged $(20.0(2-28) v 28.5(9-43)$ minutes; $\mathrm{p}=0 \cdot 02$ ). Figure 3 shows that the $50 \%$ emptying time was longer during hyperglycaemia (73.5 (46-178) minutes $v$ 104.5 (range 28-185) minutes; $p=0 \cdot 03$ ). The percentage of isotope in the stomach after 120 minutes was also increased by hyperglycaemia (from 33.5 $(5-65) \%$ to $46.5(4-85) \% ; p=0.02)$. In one patient gastric emptying was accelerated during hyperglycaemia. This patient had a $50 \%$ emptying time of 42 minutes during euglycaemia and 28 minutes during hyperglycaemia.

During euglycaemia the cumulative antral motility index was correlated with the $50 \%$ emptying time $(r=0.75, \mathrm{p}=0.02)$, but during hyperglycaemia no correlation was found $(r=0.28, \mathrm{p}=0.31)$. The number of antral contractions and number of antral contractions propagated more than $4.5 \mathrm{~cm}$ and the emptying variables were not related.

\section{Liquid emptying}

Hyperglycaemia did not affect gastric emptying of the $10 \%$ dextrose solution. The $50 \%$ emptying time was 32 (16-88) minutes during euglycaemia and 31 (18-73) minutes during hyperglycaemia $(p=0 \cdot 73)$. After 120 minutes 10 $(0-35) \%$ of the drink was still in the stomach during euglycaemia and $21(5-34) \%$ during hyperglycaemia $(p=0.34)$. The $50 \%$ emptying time of the drink showed no relation with the $50 \%$ emptying time of the solid meal. Furthermore, no relation was seen between the liquid emptying data and the motility data at 30,60 , and 120 minutes.

\section{Discussion}

This study has shown that hyperglycaemia delays gastric emptying of solids by prolonging the lag phase and by decreasing the postlag emptying rate. These results are consistent with the findings made in an earlier study showing that high blood glucose concentration delayed gastric emptying of solids in patients with type I diabetes. ${ }^{11}$ In the present study gastric emptying of the solid meal was normal in six of eight patients during euglycaemia and in only three of eight patients during hyperglycaemia. These data underline the importance of stabilising the blood glucose concentrations within the euglycemic range in diabetic patients during scintigraphic gastric emptying studies.

In our study gastric emptying of the $10 \%$ dextrose drink was not affected by the blood glucose concentration. This is by contrast with a study of Fraser et al, who found a delay of liquid emptying using the same nutrient drink. ${ }^{11}$ Although the decrease was significant, it was very small, $50 \%$ emptying time changing from 35 minutes to 41 minutes. However, the effect of hyperglycaemia on gastric emptying of liquid might have been more prominent when a high caloric drink was used, ${ }^{24}$ instead of the relative low caloric drink used in the study of Fraser $e t a l^{11}$ and our study.

In the present study blood glucose concentration in the euglycaemic arm of the study 
increased after 60 minutes from $4 \cdot 6(0 \cdot 7) \mathrm{mmol} / 1$ to $8.4(2.3) \mathrm{mmol} / \mathrm{l}$. This modest increase in blood glucose concentration may have reduced the frequency of antral pressure waves slightly, as it has been shown that even modest changes in blood glucose concentrations affect antral motility in healthy volunteers. ${ }^{14}$

The motor mechanisms responsible for the retardation of the solid emptying are complex. The present study shows that hyperglycaemia changed the antral as well as proximal duodenal contractile activity. Hyperglycaemia affected the cumulative motility index and the organisation of the antral pressure waves at the level of the antrum.

Although proximal duodenal contractile activity was decreased by hyperglycaemia, the occurrence of abnormal duodenal motility patterns was not influenced by blood glucose concentration. Phase III (like activity) was noted within two hours after the meal in three of eight patients during euglycaemia and four of eight patients during hyperglycaemia. In none of these patients was gastric emptying completed at the time the phase III (like activity) occurred. Experiments with a similar study design performed in healthy subjects did not show the occurrence of phase III activity during gastric emptying of solids. ${ }^{25}{ }^{26}$ Therefore, the early phase III observed in the diabetic patients is likely to be a pathological motor pattern. The mechanism underlying this motor abnormality is unknown, but our findings indicate that it is related to abnormal neuronal control rather than to hyperglycaemia.

Autonomic neuropathy, especially of the vagal nerves, is regarded as one of the major factors in the pathogenesis of abnormal gastrointestinal motility in diabetes mellitus. ${ }^{10}$ Previous manometric studies performed in patients with type I diabetes showed postprandial antral hypomotility, pyloric spasm, and intestinal dysmotility. ${ }^{4-6}$ In most of these studies the blood glucose concentrations were not monitored, let alone stabilised. Therefore, many of the gastrointestinal motor abnormalities reported in diabetic patients may have been influenced by raised blood glucose concentration in combination with irreversible autonomic neuropathy.

Several studies in healthy volunteers have reported a relation between the cumulative antral motility index, the number of propagated antropyloroduodenal pressure waves, and gastric emptying of solids. ${ }^{25} 26$ In our study, there was a relation between the cumulative antral motility index and the time for $50 \%$ emptying of the solid meal during euglycaemia. The fact that such a relation was not apparent during hyperglycaemia suggests involvement of other parts of the upper gastrointestinal tract. Earlier scintigraphic data showed that the percentage of solid meal remaining in the proximal stomach was directly correlated with the duration of the lag phase. ${ }^{11}$ Thus the increase in duration of lag phase found in our study suggests changes in the gastric tone. Data concerning the function of the proximal stomach in diabetic patients during hyperglycaemia are not yet available, but studies performed in healthy volunteers in the fasting period showed an increase in gastric compliance during hyperglycaemia. ${ }^{27}$

The finding that gastrointestinal motility in patients with type I diabetes with autonomic neuropathy is influenced by the blood glucose concentration has several implications. Because most previous studies did not take the blood glucose concentration into account, the percentage of diabetic patients with abnormal gastrointestinal motor function due to irreversible vagal damage, especially antral hypomotility, may have been overestimated. Therefore, the actual prevalence of delayed gastric emptying and abnormal antroduodenal motor function is not known. In the future, motility tests in diabetic patients should be performed with blood glucose concentrations within the euglycaemic range, preferably using a modified glucose clamp technique. ${ }^{23}$ Furthermore, as glucose concentrations influence gastrointestinal motility and hence gastric emptying, high blood glucose concentrations may cause further dysregulation of glucose homeostasis in diabetic patients.

In conclusion, this study has shown that hyperglycaemia reduces postprandial antral contractile activity and the propagation of antral pressure waves and decreases duodenal motility in type I diabetic patients with autonomic neuropathy. The changes in antroduodenal motility are likely to constitute the mechanism through which gastric emptying of solids is delayed during high blood glucose concentrations in these diabetic patients.

This study was supported by a grant from the Diabetes Fonds Nederland.

1 Kassander P. Asymptomatic gastric retention in diabetics (gastroparesis diabeticorum). Ann Int Med 1958; 48: 797-812.

2 Horowitz $M$, Harding M, Maddox A, et al. Gastric and esophageal emptying in insulin-dependent diabetes mellitus. $\mathcal{f}$ Gastroenterol Hepatol 1986; 1: 97-113.

3 Keshavarzian A, Iber FL, Vaeth J. Gastric emptying in patients with insuline-requiring diabetes mellitus. $A m$ f Gastroenterol 1986; 82: 29-35.

4 Camilleri M, Malagelada J-R. Abnormal intestinal motility in diabetes with gastroparesis syndrome. Eur $\mathcal{F}$ Clin Invest 1984; 14: 420-7.

5 Jebbink HJA, Bravenboer B, Akkermans LMA, van BergeHenegouwen GP, Smout AJPM. Relationship between dyspeptic symptoms and gastrointestinal motility in patients with type I (insulin-dependent) diabetes mellitus. patients with type I (insulin-depen
Diabetologia 1993; 36: 948-54.

6 Mearin F, Camilleri M, Malagelada JR. Pyloric dysfunction in diabetics with recurrent nausea and vomiting. Gastroenterology 1986; 90: 1919-25.

7 Feldman M, Schiller LR. Disorders of gastrointestinal motility associated with diabetes mellitus. Ann Int Med 1983; 98: 378-84.

8 Parkman HP, Schwartz SS. Esophagitis and gastroduodenal disorders associated with diabetes mellitus. Arch Intern Med 1987; 147: 1477-80.

9 Horowitz M, Edelbroek M, Fraser R, Maddox A, Wishart J. Disordered gastric motor function in diabetes mellitus. Recent insights into prevalence, pathophysiolos melinical recent insights into prevalence, pathophysiology, clinical relevance

10 Rundles RW. Diabetic neuropathy; general review with reports of 125 cases. Medicine 1945; 24: $111-60$

1 Fraser RJ, Horowitz M, Maddox AF, Harding PE, Chatterton BE, Dent J. Hyperglycaemia slows gastric emptying in type 1 (insulin-dependent) diabetes mellitus. Diabetologia 1990; 33: 675-80.

12 Fraser RJ, Horowitz M, Dent J. Hyperglycemia stimulates pyloric motility in normal subjects. Gut 1990; 32: 475-8.

13 Barnett JL, Owyang C. Serum glucose concentration as a modulator of interdigestive gastric motility. Gastroenterology 1988; 94: 739-44.

14 Hasler WL, Soudah HC, Dulai G, Owyang C. Mediation of hyperglycemia-evoked gastric slow-wave dysrhythmias by endogenous prostaglandins. Gastroenterology 1995. 108: $727-36$ 
15 Lam WF, De Boer SY, Masclee AAM, Lamers CBHW. Hyperglycemia reduces gastric secretory and plasma pancreatic polypeptide responses to modified sham feeding. Digestion 1993; 54: 48-53.

16 Ewing DJ, Clarke BF. Diagnosis and management of diabetic autonomic neuropathy. BMF 1982; 285: 916-8. Heddle R, Fone D, Dent J, Horowitz M. Stimulation of pyloric motility by intraduodenal dextrose in normal pyloric motility by intraduoden
subjects. Gut $1988 ; 29: 1349-57$.

18 Samsom M, Jebbink HJA, Akkermans LMA, van BergeHenegouwen GP, Smout AJPM. Abnormalities of antroduodenal motility in type I (insulin-dependent) diabetes mellitus. Diabetes Care 1996; 19: 21-7.

19 Smout AJPM, Bogaard JW, van Hattum J, Akkermans LMA. Effects of cimetidine and ranitidine on interdigestive and postprandial lower esophageal sphincter pressure and plasma gastrin levels in normal subjects. Gastroenterology 1985; 88: 557-63.

20 Fraser R, Horowitz M, Maddox M, Dent J. Organization of antral, pyloric and duodenal motility in patients with of antral, pyloric and duodenal motility in patients

21 Collins PJ, Horowitz M, Cook DJ, Harding PE Shearman DJC. Gastric emptying in normal subjects. A reproducible technique using a single scintillation camera. Gut 1983; 24: 1117-25.
22 Fone DR, Horowitz M, Heddle R, Maddox AF, Collins PJ, Read NW, Dent J. Comparative effects of duodenal and ileal intubation on gastric emptying and postprandial antral, pyloric and duodenal motility. Scand $\mathcal{f}$ Gastroenterol 1991; 26: 16-22.

23 DeFronzo RA, Tobin JD, Andres R. Glucose clamp technique: a method for quantifying insulin secretion and resistance. Am $\mathcal{f}$ Physiol 1979; 237: E214-23.

24 MacGregor, Gueller R, Watts HD, Meyer JH. The effect of acute hyperglycemia on gastric emptying in man Gastroenterology 1976; 70: 190-6.

25 Camilleri M, Malagelada JR, Brown ML, Becker G Zinsmeister AR. Relation between antral motility and gastric emptying of solids and liquids in humans. $A m \mathcal{F}$ Physiol 1985; 249: G580-5.

26 Houghton LA, Read NW, Heddle R, Horowitz M, Collins PJ, Chatterton B, Dent J. Relationship of the motor activity of the antrum, pylorus and duodenum to gastric emptying of a solid-liquid mixed meal. gastric emptying of a solid-liqui

27 Hebbard G, Samsom M, Sun WM, Dent J, Horowitz M. Hyperglycemia affects proximal gastric motor and sensory function during small intestinal nutrient infusion Gastroenterology 1996; 110: A676. 